\title{
Alegrias e tristezas no cotidiano de trabalho do agente comunitário de saúde: cenários de paixoese a afetamentos"
}

Heletícia Scabelo Galavote ${ }^{1}$

Túlio Batista Franco ${ }^{2}$

Rita de Cássia Duarte Lima ${ }^{3}$

Antônio Márcio Belizário ${ }^{4}$

GALAVOTE, H.S. et al. Joy and sadness in the daily activities of community health agents: scenarios of passions and emotions. Interface (Botucatu), v.17, n.46, p.575-86, jul./set. 2013.

This study sought to unravel the working process of community health agents based on Espinosa's emotions theory. Meetings were taken to be the analysis unit, and the aim was to understand them with regard to the dynamics of care production, with analysis on emotions that were expressed through joy and sorrow, and on their effects on the agents' work. This was an exploratory and descriptive qualitative study, undertaken at the Jardim Catarina Unit, São Gonçalo, Rio de Janeiro, Brazil. Data were gathered through semi-structured interviews with ten community health agents, and ethnographic observation. The study revealed that the agents had multiple facets, with exposure to the emotions of the relationships that they maintained, and variation between recognition of and submission to the logic imposed, thus resulting in joy and sorrow, and respectively increasing or decreasing their power to act.

Keywords: Family health. Community health workers. Subjectivity.
O estudo busca desvendar o processo de trabalho do agente comunitário de saúde (ACS) com base na teoria das afecções de Espinosa. Considera o encontro como uma unidade de análise, e pretende compreendê-lo na sua dinâmica de produção do cuidado, analisando as afecções que se expressam por alegrias e tristezas e os seus efeitos no trabalho do ACS. Trata-se de estudo exploratóriodescritivo, de caráter qualitativo, realizado na Unidade Jardim Catarina, São Gonçalo, Rio de Janeiro, Brasil. Os dados foram coletados em entrevista com dez ACS's, por meio de roteiro semiestruturado e observação etnográfica. $O$ estudo revela um ACS múltiplo, exposto às afecções das relações que mantém, variando entre 0 reconhecimento e a submissão às lógicas instituídas, resultando em alegria e tristeza, aumento e redução da sua potência de agir, respectivamente.

Palavras-chave: Saúde da Família. Agentes comunitários de saúde. Subjetividade.

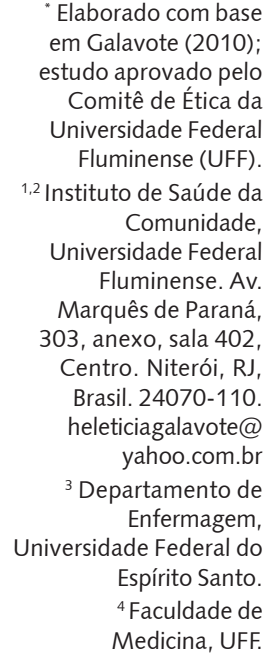

Elaborado com base em Galavote (2010); estudo aprovado pelo Comitê de Ética da Universidade Federal Fluminense (UFF).

${ }^{1,2}$ Instituto de Saúde da Comunidade, Universidade Federal Fluminense. Av. Marquês de Paraná, 303, anexo, sala 402, Centro. Niterói, RJ, Brasil. 24070-110. heleticiagalavote@ yahoo.com.br

${ }^{3}$ Departamento de Enfermagem,

Universidade Federal do Espírito Santo. ${ }^{4}$ Faculdade de Medicina, UFF. 


\section{Introdução}

A temática da alegria e da tristeza no cenário do trabalho - foco deste estudo - é fundamentada pela leitura feita por Deleuze da teoria das afecções de Espinosa (Deleuze, 2002). Traz algumas categorias da teoria do trabalho, na medida em que se reconhece que há um "espaço de liberdade" no exercício do trabalho em saúde, que autoriza negociações, invenções e modulações que referem ao trabalhador um protagonismo mediado pela sua singular proposta ético-política de cuidado. Quando existe uma "interdição" dos desejos inscritos no campo do trabalho, surge o domínio do sofrimento e da luta do agente comunitário de saúde (ACS) por agenciamentos subjetivos inscritos em determinado território de significações de tudo que o cerca: os usuários, sua equipe, o trabalho e cuidado em saúde.

Partimos, também, do pressuposto de que todo trabalhador opera segundo suas intencionalidades e desejos, e, sob este prisma, Rolnik (2006) ressalta que o desejo se constitui em processo de produção de universos psicossociais, é como uma força propulsora que põe o sujeito em movimento na construção do mundo, do lugar social em que vive. No trabalho em saúde, o trabalhador é compelido ao encontro com os outros, trabalhadores e usuários, e, assim, entra em relação o tempo todo. Entre os corpos que se encontram, forma-se um "campo de consistência", trânsito de intensidades no exercício do poder de afetar e ser afetado, que tem como efeito um estado de alegria ou tristeza, aumento ou redução da potência de agir sobre o mundo.

Sobre os afetos no corpo e sua potência para a ação, Deleuze (2002, p.33-4) diz o seguinte:

... quando encontramos um corpo exterior que não convém ao nosso (isto é, cuja relação não se compõe com a nossa), tudo ocorre como se a potência desse corpo se opusesse à nossa potência, operando uma subtração, uma fixação: dizemos nesse caso que a nossa potência de agir é diminuída ou impedida, e que as paixões correspondentes são de tristeza. Mas, ao contrário, quando encontramos um corpo que convém à nossa natureza e cuja relação se compõe com a nossa, diríamos que sua potência se adiciona à nossa: as paixões que nos afetam são de alegria, nossa potência de agir é ampliada ou favorecida.

O corpo sofre os efeitos do encontro aumentando ou reduzindo sua potência de agir, se as paixões forem alegres ou tristes, respectivamente. E isto interessa para este estudo quando discutimos o trabalho em saúde, porque, se temos como pressuposto que o cuidado se produz com base em um encontro, importa verificar que afecções o trabalhador vai apresentar no momento deste encontro, e a variação de sua potência, os efeitos na sua possibilidade de realizar este cuidado quando em relação com o usuário, que, também, é parte ativa do encontro e seus afetos.

No complexo cenário do trabalho em saúde, há uma mistura de afetos circulantes nas múltiplas relações, que se incorporam ao contexto de atuação dos trabalhadores, que dispõem de uma subjetividade flexível, experimental e processual, sendo detentores de uma força inata de criação. Isto só é possível porque o trabalho em saúde é centrado no trabalho vivo (Merhy, 2002), que se exerce com relativa liberdade, ou seja, o trabalhador tem a possibilidade de governar seu próprio processo de trabalho, possibilitando a invenção e criação. Associamos a esta ideia a de que a subjetividade tem força operatória e se expressa no trabalho em saúde, tendo como energia propulsora o desejo, apoiado nas redes que se formam no exercício do seu trabalho. A articulação entre o desejo como força propulsora do trabalho, as redes no plano da micropolítica, e o trabalho vivo como plataforma por onde operam os processos produtivos na saúde caracterizam a produção subjetiva do cuidado (Franco, Merhy, 2011).

A subjetividade, na concepção de Deleuze (2002) e Guattari e Rolnik (2005), é inerente à ideia de "outro", indivíduo como processo e produto, um campo processual de forças moventes e formas que emergem dessas forças. Barros (2008) afirma que o humano é formado por um processo coletivo e em rede, dinâmico, inacabado.

Deleuze sugere que todos os componentes de um determinado contexto interpretativo são constituídos e se conformam através de uma multiplicidade de signos que são singulares, únicos para cada matéria ou sujeito, de modo que "a unidade de todos os mundos está em que eles formam sistemas de signos emitidos por pessoas, objetos, matérias; não se descobre nenhuma verdade, não se 
5 “Um Corpo sem Órgãos é feito de tal maneira que ele só pode ser ocupado, povoado por intensidades". "O CsO é o campo de imanência do desejo, o plano de consistência própria do desejo (ali onde o desejo se define com processo de produção, sem referência a qualquer instância exterior, fatal que viria torna-lo oco, prazer que viria preenchê-lo)" (Deleuze, 1996, p.13, 15). Este artigo toma este conceito para pensar as relações de trabalho na saúde, já que procura colocar, em análise, o entre no encontro trabalhador e usuário, na relação de produção do cuidado. aprende nada, se não por decifração e interpretação" (Deleuze, 1987, p.5). Essa discussão da representatividade dos signos que emergem das relações entre os sujeitos, nos leva a pensar na figura da aranha. Mas por que uma aranha? Deleuze (1987) utiliza a figura deste artrópode para exemplificar o que é um corpo sem órgãos ${ }^{5}$. Assim, a aranha, enquanto um corpo sem órgãos, percebe o meio através das vibrações, seria movida unicamente por signos que atravessam o seu corpo como uma onda e a tornam capaz de saltar em busca da presa, sendo que, sem olhos, sem nariz, sem boca, a aranha responde unicamente aos signos e é atingida pelo menor deles. Os signos, para a aranha, seriam a sua própria essência, a essência do próprio existir que a impulsiona em múltiplas direções e entre múltiplos sentidos, sendo eles que disparam o ato de tecer com cada fio se movimentando por este ou aquele signo. O corpo sem órgãos pode ser entendido como o corpo afetivo, que se manifesta por intensidades.

O trabalho em saúde opera sempre em redes (Franco, 2006), e o ACS é, por excelência, um trabalhador onde isto se encontra fortalecido, operando sempre em fluxos-conectivos que traçam uma cartografia no seu microcosmo, operando com base na micropolítica do seu processo de trabalho. Ele é construtor de sua teia, que é singular para cada sujeito e que se caracteriza por sua tenacidade, resistência e elasticidade, de forma que se estende por diferentes territórios. Essa teia se define, especialmente, pelos encontros e agenciamentos de que o ACS é capaz, na permanente construção de territórios existenciais que conformam campos magnéticos de produção de sentidos e de afetos no seu processo de trabalho.

Conformamos, como campo problemático deste estudo, os efeitos produzidos a partir do encontro entre o ACS e o mundo do trabalho em saúde e suas multiplicidades, tendo-o como a "unidade de análise", ou seja, consideramos que são nos encontros, e com base no seu trabalho, que o ACS realiza o cuidado. Trazer este discurso para o estudo da alegria e da tristeza no trabalho do ACS nos remonta a pensar e buscar apreender o efeito real das relações que são construídas e desconstruídas por ele no encontro com outros, e compreender como são manifestados seus efeitos nos cenários do trabalho.

\section{Aspectos metodológicos}

Esta investigação constitui um estudo qualitativo que busca caracterizar e analisar o trabalho dos agentes comunitários de saúde em equipes de Saúde da Família, tendo os afetos expressos pela alegria e tristeza no cotidiano de trabalho como analisador do processo de trabalho do ACS e sua potência de agir para o cuidado.

A pesquisa foi desenvolvida em Unidade de Saúde da Família de um município na região metropolitana do Rio de Janeiro. O critério para escolha da Unidade foi o de estabilidade da equipe de Saúde da Família, que permanecia no trabalho desde 2001, com baixa rotatividade de trabalhadores e completa, ou seja, composta por: um médico, enfermeiro, auxiliar de enfermagem, agentes comunitários de saúde e odontólogo.

Foram convidados todos os agentes comunitários de saúde da equipe selecionada que, voluntariamente, aceitaram participar da pesquisa. Os dados são produto da relação intensa entre o pesquisador e suas fontes; se reconhece a singularidade de ambos, e suas implicações neste movimento que caracterizamos como de produção conjunta.

A técnica de investigação escolhida para a produção dos dados empíricos foi a entrevista, que teve como base um roteiro semiestruturado que aborda: a 
caracterização dos sujeitos em estudo, processo de trabalho na ESF, concepções acerca do tema, significado do trabalho, satisfação, insatisfação, alegrias e tristezas no agir cotidiano, sugestões e desafios, dentre outros.

Foram efetuadas anotações e gravações sobre a aproximação ao campo e aos participantes, e atenta observação, como a das expressões de silêncio e a linguagem corporal. Foi realizada, assim, uma observação direta da realidade e do cotidiano de trabalho do sujeito em estudo, a fim de dar passagem a aspectos algumas vezes ocultos nos discursos dos participantes.

Com o objetivo de identificar a dinâmica que se inscreve no trabalho cotidiano do ACS, foi realizada, como um método complementar, uma imersão do pesquisador no trabalho dos agentes, através de uma observação do tipo etnográfica, que foi construída por um período de quatro semanas nos cenários da pesquisa, com posterior registro das nuances deste cotidiano no diário de campo, que teve um caráter complementar na análise dos dados.

A análise foi baseada nos significados apreendidos nas entrevistas, das quais foi feita leitura exaustiva, buscando-se os principais elementos que compõem o problema em estudo. Procurou-se uma análise e busca de sentidos para as questões que o estudo se coloca.

Aplicou-se a Resolução n 196/96 do Conselho Nacional de Saúde para questões éticas.

\section{Resultados e discussão: o trabalho cotidiano do ACS}

Situamos o trabalho enquanto um regime de produção de saberes, no qual há a contínua produção dos sujeitos trabalhadores, ao mesmo tempo em que estes produzem o mundo do cuidado. Eles são, em sua essência: desejos, necessidades, interesses em conjugação e conflitos, que transitam por diferentes territórios inventando o mundo e inventando a si mesmos. Reconhecemos que o mundo do trabalho é criação e uso de si, mas também luta e resistência ao trabalhar e a si (Santos, Barros, 2007). O protagonismo do trabalho enquanto criação é regido por singularidades, mediadas pelas tecnologias de trabalho, constitutivas de cada trabalhador, que opera o seu processo de trabalho e recria o trabalho do outro por meio da tríade saber, poder e subjetividade, que estão em permanente implicação. Nesse sentido, a busca da significação do trabalho e o entendimento das relações que são estabelecidas no campo da produção devem se fundamentar no discurso e nos atos de cada trabalhador, o que nos levou a indagar, ao ACS, o que ele entende como reconhecimento da profissão, os agenciamentos de que é capaz e os sistemas abertos de conexões que constituem o seu agir enquanto trabalhador da saúde. A profissão de ACS foi significada como transformação, informação, aproximação e solidariedade, como $\operatorname{diz} \mathrm{A} 8$ :

“Eu acho que o papel do agente comunitário é algo extremamente atuante, acaba sendo uma pessoa que tem a missão de transformar, sempre tem a missão de transformar, de mudar e acaba sendo um grande formador de opinião. O papel do agente é estar ajudando a população dentro de suas carências". (A8)

Há uma ideia corrente que atribui, ao ACS, uma produção social de identidade que o associa a alguém com "pendor" para o cuidado, compaixão para com o outro (Ferreira, 2008) - no entanto, ele é um ser múltiplo, que pode ser isto, ou muitas outras coisas; ele se apresenta como nômade, já que transita por diferentes territórios existenciais, de saberes e práticas, construindo e desconstruindo mundos, em múltiplos encontros. No cenário complexo, eles se reconhecem como um "elo de ligação" entre os usuários e a equipe de saúde, a partir da constatação de que formam partes de uma corrente que mantém interligados os usuários e os profissionais da equipe.

"O papel do agente eu acho muito importante dentro da comunidade, porque é você que capta todos os problemas que têm dentro do bairro e traz para a equipe, para o médico que trabalha mais na Unidade do que na comunidade; ele não é tão ativo como o agente comunitário. O agente na comunidade ele é tudo, ele é que é o elo mais forte dentro dessa 
corrente, se não tiver o agente comunitário não tem como o médico e a enfermeira trabalhar". (A5)

A construção social do ACS enquanto profissional da saúde faz com ele se reconheça enquanto "elo de ligação", como dito anteriormente, o que lhe impõe uma grande responsabilidade em estabelecer e fazer perdurar o vínculo entre os profissionais da equipe e os usuários, o que não depende essencialmente do seu trabalho, pois não é possível, ao ACS, fazer vínculo pelos outros membros da equipe.

Silvia e Dalmaso (2002) apontam que o trabalho do ACS pode ser descrito sob dois prismas, já que um dos polos se refere à figura de "mensageiro" e mero canal de comunicação entre o serviço e a comunidade, ou, ao contrário, pode se constituir em um "agente reformador" capaz de operar mudanças na assistência ao usuário. Segundo a autora, oscilam de forma polar as vivências pessoais acumuladas, que seriam imprescindíveis, e, até mesmo, bastariam para a constituição do ACS; e, por outro lado, os domínios técnicos de certos procedimentos em saúde que garantiriam uma reforma nuclear e institucional no campo da saúde.

A5 reforça a vertente solidária e relacional do trabalho que exerce, ao compor uma ideia do trabalho do ACS que se fundamenta no atendimento das necessidades de saúde da comunidade e nos encontros que afetam mutuamente os atores envolvidos, ao discursar:

"Ser agente comunitário de saúde é estar ali, o dia-a-dia, você estar dentro da casa das
pessoas procurando ajudar no que você pode, é amenizar um pouco essa carga de
problemas, mostrar o caminho, ensinar os direitos às pessoas". (A5)

A motivação enquanto desejo de permanecer na profissão foi referenciada, neste estudo, como: a possibilidade de ajudar o outro, a construção de vínculos de amizade, e o reconhecimento de que o trabalho realizado é capaz de disparar processos de autocuidado e ressignificação por parte dos usuários, que se empoderam do seu próprio cuidado e reconhecem, no ACS, um agente de transformação e resolutividade.

"O que motiva é a amizade, você acaba se envolvendo com alguns casos e quer ajudar mesmo, quer estar ali dando uma força". (A1)

"O que me dá prazer é ver as pessoas precisando de uma medicação, de uma consulta, uma pessoa carente precisando de um remédio, aí dá força para a gente trabalhar, poder ajudar". (A2)

O resultado do trabalho constitui, para os agentes, a maior motivação, a partir do entendimento de que o outro se conforma, também, como um ser desejante, com poder para gerir e afetar, apesar dos fracassos interpostos no encontro entre o agente comunitário e os usuários e a comunidade, como nos $\operatorname{diz}$ A8:

"A motivação não vem dos gestores, não vem do modelo de estrutura adotado por eles, mas sim da população, porque quando você percebe que uma pessoa que você acompanhou, no meu caso são dez anos, e muitas crianças a gente acompanhou desde pequeno, isso para mim acaba sendo uma grande vitória, dá uma satisfação muito grande perceber que as pessoas estão saudáveis, têm qualidade de vida, estão se cuidando". (A8)

No encontro com os usuários e a comunidade, o ACS reconhece diferentes signos que se conformam de forma verbal ou não verbal; os signos atravessam o ACS pelos afetos que é capaz de provocar, ou seja, resultando na produção de alegrias ou tristezas com base neste encontro, com o aumento ou a diminuição da potência para agir do trabalhador, em processos contínuos de construção e desconstrução nas relações que compõem. A interpretação de alguns signos emitidos pelos usuários, 
como, por exemplo, um sorriso de satisfação e gratidão, gera a instância reconhecimento, é como se o ACS, neste encontro, realizasse sua potência como trabalhador da saúde, assim, ele é possuído por afetos cujos efeitos aumentam a sua potência de agir. Nesta relação, ele é capaz de produzir novos signos, que também são emitidos e que, por sua vez, afetam o usuário, e isto produz efeitos sobre o mesmo - como está descrito na ideia de Clínica dos Afetos discutida por Franco e Galavote (2010), que agrega, ao conceito de Foucault (2004) de "clínica do olhar", anatômica, morfológica, a clínica dos órgãos, a ideia de uma clínica afetiva que compõe e complementa esta, demonstrando que o sensível, que há em nós e no campo de intensidades entre o trabalhador e o usuário, tem força operatória sobre o projeto terapêutico. Assim, um signo gerado no campo de produção do cuidado se conecta à percepção de cada sujeito envolvido e compõe com novos saberes e poderes, sendo o último considerado enquanto desejo de perpetuação do novo, enquanto produção e criação.

"A maior satisfação é quando eles reconhecem, porque nem todo mundo reconhece o seu trabalho. Mas, alguns reconhecem muito, a ponto de nos presentear, acho que é mesmo o reconhecimento". (A1)

"A maior satisfação é quando você consegue resolver os problemas deles, ver que estão satisfeitos, ver a gratidão, construir amizades, ver que a comunidade está bem, ver os frutos do trabalho". (A15)

O ACS capaz de perceber o mundo e suas relações através dos signos, intensidades, ou seja, o "ACS-aranha", enquanto construtor inato de teias, sobre as quais opera o campo da micropolítica do trabalho, é, então, afetado pelo reconhecimento oriundo do encontro com a comunidade, experienciando um aumento da sua potência, expressa como desejo e paixões alegres, ao mesmo tempo em que emite signos representados pelas atividades com os usuários, buscando resolutividade e satisfação no cuidado. Exerce a sua sensibilidade enquanto "corpo sem órgãos", vibrátil, que é capaz de apreender os signos gerados pela extremidade do fio de seda que transmite os afetos do usuário e a comunidade, e emitindo novos signos que são reconhecidos pelos usuários e que garantem a coesão da teia, à medida que mantém a circularidade produtiva enquanto território de eclosão de afetos e paixões.

\section{A busca pelo reconhecimento e afecções no trabalho do ACS}

O ACS busca o reconhecimento do seu trabalho, e este passa a ser visualizado na circularidade produtiva de uma "teia" construída por ele, ou seja, no conjunto das relações que mantém no âmbito do seu trabalho, dentro da Unidade com a equipe ou na comunidade à qual atende. Nesse processo, ele se move, transita pelas extremidades do processo de trabalho da equipe, e, paradoxalmente, tem uma centralidade no cuidado aos usuários. Se vale, fundamentalmente, da coesão e tenacidade dos "fios de seda" da sua rede, completando a metáfora da aranha e sua capacidade de interpretar os signos, mencionada no livro Proust e os Signos (Deleuze, 1987); o ACS se vale do seu conhecimento, e da dimensão afetiva de percepção do mundo, para realizar seu trabalho, e busca pelo reconhecimento. Sob este aspecto, o reconhecimento é expresso, segundo Honneth, citado em Mendonça (2008), como estima social, sendo exercido por meio de valores, como a solidariedade, e estando relacionado à manutenção da estima que determina o seu impacto no encontro estabelecido.

O fato de o ACS considerar o reconhecimento como um resultado a ser obtido a partir do cuidado aos usuários, que realiza no seu trabalho, e pode resultar em afecções alegres, não garante que ele seja percebido pelo outro como cuidador, já que a percepção dos afetos produzidos depende do "olhar vibrátil" dos corpos em relação. Na relação de cuidado, nada é previsível, por exemplo, pode haver a imposição de um cuidado dominador e controlador do profissional sobre o usuário, em busca do êxito na mudança dos hábitos de vida do usuário, operando o conhecimento como verdades que o ACS adquire dos demais profissionais da equipe, sem diálogo com o usuário. O ACS pode, então, atuar como um "amolador de facas", que, segundo Barros (2008), atuam com base em uma ação "complacente, microscópica e cuidadora" e que exercem um cuidado de tutela, no qual, o outro é tido 
como fraco e destituído da sua subjetividade. O ACS "amolador de facas" se desvenda nas ações de um cuidado controlador e operante, o que fica nítido na fala de A5 que será apresentada a seguir, ao citar o cuidado que direciona aos usuários hipertensos e diabéticos. Mas, nem sempre o cuidado de tutela é percebido pelo ACS enquanto diminuição da criação coletiva, e o conhecimento que direciona o seu trabalho cotidiano constitui de forma intencional, ou não, um "sistema regional de lutas, uma postura ético-estética-política, cuja assunção delimita certos territórios de embate" (Barros, 2008, p.280-1).

"O que me faz feliz na profissão é você pegar um paciente com descontrole da pressão arterial e trazê-lo para a unidade, controlar a sua pressão. O maior desafio é controlar todos os hipertensos e diabéticos, fazer eles entenderem que o que a gente fala deve ser seguido". (A5)

A cisão da teia produzida pelo ACS no cotidiano origina-se dos processos de captura do seu trabalho, estimulados pelos sentidos atribuídos ao seu trabalho, aos quais se atribui menos valia em relação aos saberes instituídos. A construção social e subjetiva do trabalho na saúde, incorporado pela equipe, o coloca à margem dos processos decisórios desta, e reconhecendo a limitação do seu saber-fazer perante a diversidade com que se depara no trabalho. Este cenário faz com que sua função-nômade seja interditada, e o ACS passa a operar com o imaginário que associa competência para cuidar, com capacidade no manejo de procedimentos.

"O trabalho do agente não aparece porque ninguém dá valor ao nosso trabalho, eu prefiro estar na rua, quando você trabalha aqui dentro são pessoas diferentes, pensamentos diferentes. É muito conflito, cada pessoa tem um perfil de trabalho". (A5)

A3 responsabiliza a organização real do trabalho pela dificuldade em acessar a equipe, reconhecendo que a captura do trabalho vivo pela rigidez de uma gestão centralizadora produz um desarranjo nos encontros com a mesma.

“Eu vejo a necessidade de um dia na semana parar e colocar as cartas na mesa, o médico e o enfermeiro não têm muito tempo para se reunir, estar junto, dialogar com a equipe e jogar as cartas na mesa, fazer uma arrumação". (A3)

A valorização social do trabalho dos outros profissionais, em detrimento do ACS, produz no ACS a experiência do fracasso e insatisfação, e dificulta o acesso aos profissionais da equipe, em especial, ao médico. Em geral, os trabalhadores se isolam no seu núcleo profissional específico, e não reconhecem os saberes inscritos no trabalho do ACS - que se situa no campo mais amplo cuidador (Merhy, 2002; Campos, 2000) - e, sobretudo, sua implicação no ato de cuidar. Franco, Bueno e Merhy (1999) nos apresentam a ideia de que a organização da assistência à saúde se ancorou em um modelo de atenção centrado em procedimentos, estando a produção do cuidado atrelada às tecnologias duras e leve-duras, e tendo a medicalização como o cerne do trabalho que é realizado no cotidiano dos serviços de saúde.

"Às vezes o médico dificulta, tem aquela hierarquia, o agente comunitário é o agente comunitário e o médico é o médico. Tem médico que acha que o agente não é nada, eu tenho muita dificuldade em lidar com isso". (A2)

“Ele é assim, tem que ser tudo como ele quer, do jeito dele, o médico sou eu e eu que sei a necessidade, mas somos nós que estamos na rua e sabemos quais são as deficiências e dificuldades". (A4)

Sob esse aspecto, é proposto o reconhecimento do trabalho realizado pelo outro e com o outro trabalhador, reconhecendo-o como parte constitutiva do trabalho coletivo em saúde. Na verdade, o que 
existe é uma desigual valorização social dos diferentes trabalhos, o que nos remete à desigualdade entre os trabalhos realizados que se traduzem em relações de poder e hierarquia entre os trabalhadores das diversas áreas de atuação. Essa hierarquia está vinculada à gestão, estrutura organizacional, áreas profissionais e diferentes trabalhos, o que é gerador de relações de mando e manutenção do status quo, reproduzindo a divisão técnico-social dos modos de produção (Galavote, 2007).

Verifica-se, nas relações de poder inscritas no interior de uma equipe de saúde da família, ou podese verificar, também, em qualquer nível da gestão, que a dominação se dá por redução da potência do outro através de relações coercitivas de gestão do trabalho, ou do não-reconhecimento profissional, ou qualquer outra forma de agir que vai em direção da produção das muitas tristezas vivenciadas cotidianamente no trabalho. A limitação imposta pela gestão e a própria organização do trabalho incide no ACS, levando-o a um estado de tristeza, à diminuição da sua potência de agir, e engessando a criatividade e inventividade desse trabalhador. Barros (2008) caracteriza este processo como uma "amputação do trabalhador de sua iniciativa", que ocorre a partir do silenciamento dos movimentos de criação.

\section{As tecnologias e o trabalho do ACS}

"O que dificulta o nosso trabalho é o número reduzido de consultas, a falta de medicação, a falta de infra-estrutura. Eu quero fazer alguma coisa, mas fazer o quê? Não posso fazer nada, não tenho como fazer nada". (A6)

A afirmativa acima é paradoxal em relação ao que pode um ACS, visto que o processo de trabalho centrado nas tecnologias relacionais não depende exclusivamente dos recursos acima; no entanto, há no imaginário social a ideia de que conhecimento válido é o que se inscreve no núcleo duro das profissões, e práticas que pedem procedimentos, uma subjetividade biomédica que opera e faz do ACS mais um trabalhador queixoso, vitimado pela falta de materiais, equipamentos, especialistas.

A diminuição da potência de ação do ACS no encontro com a gestão do trabalho se traduz na destituição do trabalhador do seu saber-fazer específicos, e o impossibilita de realizar algo no âmbito do não-prescrito, o que nos faz pensar na primazia do trabalho morto, que opera por uma razão instrumental, sobre o trabalho vivo, que pode ser trabalho criativo, o que leva à perda da liberdade e criatividade.

"O maior desafio é a falta de estrutura que a gente tem com relação a materiais, não tem muito o que proporcionar à pessoa, o que eu mais falo é: 'eu não posso, eu não tenho, não tem remédio hoje'. Eu acho que a gente tem capacidade para fazer mais coisas, de atender melhor a comunidade, o que a gente faz aqui é marcar consulta". (A7)

O agente comunitário deveria operar centralmente no campo das tecnologias relacionais, associadas a uma aguda percepção dos afetos, e signos. A2 destaca este aspecto no seu processo de trabalho.

"A paciência, o amor a eles, a compreensão. O que eu mais utilizo é o diálogo, a fala, a escuta, a informação, o conhecimento que eu adquiri na minha experiência diária e nas capacitações que recebi". (A2)

O campo de conhecimentos do ACS se constrói com base nos conhecimentos que ele adquire no convívio com os profissionais da equipe, em programas de educação em serviço, e no conhecimento que traz consigo das experiências de vida. Estas, quando processadas como vivências em que a sua própria existência no mundo esteve em análise, podem produzir também uma subjetividade que, para Deleuze (2001), representa uma dupla potência, à medida que crê e inventa, presume poderes secretos e supõe poderes abstratos, distintos. 


\begin{abstract}
“Eu já fiz vários cursos, me ajudou muito, a lidar com as pessoas, entender o que o médico fala, o que o enfermeiro fala, antigamente a gente não entendia, melhorou muito. Agora eu trabalho com o conhecimento que trago da minha vida e com os novos conhecimentos que adquiri com a comunidade e na Unidade". (A1)
\end{abstract}

$\mathrm{Na}$ escuta dos ACS's percebe-se que a produção de saberes no encontro com a equipe de saúde se faz de forma verticalizada, com a mera transmissão de conhecimentos que possam instrumentalizar o seu agir cotidiano, ou seja, ele absorve o discurso do médico e do enfermeiro e o aplica no encontro com a comunidade. Fica claro que o ACS é considerado, pela equipe, como uma "página em branco", de forma que os conhecimentos que ele traz de suas experiências de vida não encontram lugar em um espaço de supremacia do saber biomédico, e um processo de trabalho centrado no campo das tecnologias duras e leve-duras descritas por Merhy (2002), como equipamentos e saberes bem estruturados. O mesmo autor reforça ainda a ideia de que o trabalho em saúde pode assumir dois escopos, ou seja, de um lado, pode estar centrado em um ato prescritivo que legitima um modelo centrado no saber médico hegemônico, produtor de conhecimentos, e, por outro lado, pode se dar sob a forma de relações intercessoras estabelecidas no trabalho vivo e em ato que produz um cuidado gerador de ganhos de autonomia por parte do usuário.

A6 reconhece as falhas no processo de produção de saberes no encontro com os trabalhadores da equipe, e afirma que "é a experiência da rua que faz você aprender", já que, no encontro com a comunidade, o ACS é capaz de gerir o seu agir e exercitar a criatividade e inventividade do seu saberfazer, ou seja, no espaço da comunidade, ele é livre para produzir o cuidado e estabelecer novos encontros. Sob este aspecto, entendemos que os ACS's, assim como todos os trabalhadores da saúde que estão implicados com a produção do cuidado, controlam seu microcosmo, o lugar onde especificamente trabalham, em função da liberdade que lhes é atribuída pelo trabalho vivo, na sua atividade cotidiana. Como sugerem Merhy e Franco (2003), isso pressupõe que o modelo assistencial se constitui, sempre, a partir de contratualidades entre todos os que se encontram no plano da produção do cuidado, mesmo que esta pactuação se dê sob forte tensão, a forma de organização da assistência é produto dela.

O trabalho do ACS sugere uma imagem triangular e intercessora entre as instâncias tristeza/alegria, trabalho e reconhecimento. Trazemos esta referência para reafirmar que o trabalhador pode experienciar cotidianamente diferentes afetos que determinarão o impacto do trabalho sobre o trabalhador, sobre o produto e o 'consumidor'. No entanto, é nítido que o ACS, ao compor sua teia de relações, fica exposto ao atravessamento de diferentes signos e afetos, que se conformam de modo circular e contínuo, e não apenas de modo hierarquizado, como na pirâmide. Assim, o estudo do trabalho do ACS revela a cartografia de uma teia com linhas, que se rompem e se recompóem de acordo com a natureza do encontro estabelecido e os afetos que são compostos nesta coesão.

\title{
Considerações finais
}

O desvendamento do trabalho cotidiano do ACS, neste estudo, revela um trabalhador híbrido, que permeia territórios distintos da tríade poder, saber e subjetividade. O que existe é uma lacuna entre os muitos sentidos que dão para a profissão de ACS, construídos socialmente, como o que consta na Lei $10.507 / 2001$, que cria a profissão e estabelece, como função, a prevenção de doenças e promoção da saúde. Os próprios agentes e outros trabalhadores criam um elo de ligação entre equipe, comunidade e famílias de usuários, o mesmo citado por Ferreira (2008), segundo a qual os ACS's "podem em alguns momentos ter mais pendor para ajuda solidária e em outros menos, ou quem sabe até não ter, isto não significa que essa característica seja inerente à subjetividade do agente e a sua presença seja condição para os bons encontros" (Ferreira, 2008, p.44).

Percebe-se que a profissão de ACS não se fundamenta em vocação e pendor solidário, nem mesmo no "elo de ligação" ou, exclusivamente, na promoção da saúde; mas ele está inscrito em um território de conflitos, subjetividades, desejos, micropoderes, e que operam, sobretudo, com base em um 
recorte interessado da realidade; e sua existência no mundo do cuidado o mantém desorganizado, subjetivação em processo permanente, onde as relações no campo social o agenciam, e ele, ao mesmo tempo, produz este campo social, em uma permanente, intensa, produtiva e inconstante dobra.

Assim como não há uma identidade que se impõe, não há como definir um perfil para o ACS, já que é um trabalhador que, como outros, inventa e reinventa cotidianamente o seu processo de trabalho. Devemos falar em singularidade como expressão única em um tempo e espaço que também se movem; subjetivações, e não em perfil, já que estamos falando de um trabalhador policênico, que opera o seu próprio processo de trabalho com altos graus de liberdade.

O estudo do trabalho do ACS nos revelou a figura da aranha de Deleuze (1987), já que o ACS, assim como os demais trabalhadores da saúde, opera o cuidado no momento dos múltiplos encontros com o usuário e a comunidade, ou seja, o trabalho que realiza é eminentemente relacional, intercessor. Através do seu corpo sem órgãos, expresso enquanto percepção e subjetivação, é capaz de sentir os signos emitidos pelos diferentes atores - e que, quando interpretados, têm a potência de afetá-lo, aumentando ou diminuindo sua potência para agir - e emitir signos que garantem ou não a coesão da teia.

No encontro com o usuário e suas necessidades de saúde, o ACS pode operar um cuidado-políticoafetivo, no qual há ganhos de autonomia por parte do usuário, que é visto como coautor no campo da produção do trabalho; ou gerir um cuidado-procedimento-centrado, exercido através do emprego de tecnologias duras e leve-duras que, quando mal empregadas, produzem heteronomia. Surge, então, a imagem do ACS "amolador de facas", que impõe, ao outro, um cuidado centralizador e dominador, que destitui o sujeito de sua própria inventividade e autonomia. Assim, o ACS não é o trabalhador com um dito "perfil" proposto nas leis, ou sentidos socialmente construídos; e surge uma figura múltipla, protagonista do seu trabalho, o que torna ingênuas as concepções que o consideram enquanto vítima das amarras de um trabalho engessado, que, na verdade, é produzido, também por ele, no seu agir.

Em acordo com Silva e Dalmaso (2006), de que a indefinição do papel do ACS dificulta a delimitação do seu desempenho enquanto integrante da instituição equipe de saúde, considero que essa indefinição é, a um só tempo, sua maior dificuldade e sua maior potência. Fica claro que os encontros geradores de tristeza são experimentados, especialmente, na relação com os profissionais da equipe e a própria gestão do trabalho, que acabam por romper a teia que o ACS tece no seu agir cotidiano, e que, uma vez recomposta, acaba por apresentar ranhuras e cicatrizes que redirecionam a natureza do encontro estabelecido. As ranhuras representam as linhas de fuga,

servem de dispositivos a diferentes agenciamentos [...] podendo o trabalhador apresentar ou não identidade com a comunidade, ser ou não solidário, servir mais o menos como mediador a depender de como tenha ocorrido, em sua vida, os processos de subjetivação e o quanto permite os afetos passarem, isto é, o limiar de desterritorialização que conseguem suportar. (Ferreira, 2008, p.44)

Como considerações, cabe-nos a confluência de dois conceitos apresentados por Deleuze (2002), o de "bom ou mau", que caracterizam a polaridade que encontramos no trabalho do ACS e nos encontros que ele estabelece. Para o autor, será dito bom ou forte aquele que é capaz de organizar os encontros, de se unir ao que lhe convém e que é capaz de aumentar a sua potência, já que essa bondade tem a ver com dinamismo, composição de potências. Por outro lado, o mau ou fraco é aquele que vive ao acaso dos encontros, sofrendo passivamente as conseqüências e tendo revelada, continuamente, a sua redução de potência. Desta forma, nos deparamos com um ACS transeunte, que faz trânsito entre o bom e o mau, que permeia diferentes territórios e que é capaz de direcionar os encontros, com gerência do seu processo de trabalho, o que retira-nos a ideia de vitimação desse trabalhador perante a captura do seu trabalho pelos saberes instituídos da equipe ou, mesmo, pela rigidez da organização do trabalho. Podemos considerar, também, a possibilidade de um mesmo ACS reunir estas características divergentes, em momentos diversos, que, a princípio, pareceriam contraditórias, mas expressam o ser múltiplo que é. A diversidade caracteriza em muito o agir cotidiano do ACS, impossibilitando uma análise que generalize a sua conduta, já que deve ser vista como uma variação de possibilidades de práticas de cuidado ao usuário. 
A indefinição é uma das vivências mais profundas no cotidiano de trabalho do ACS, não somente porque não lhe seja dado a priori um corpo de conhecimentos bem definidos e, sim, pelo fato de que o seu trabalho se constitui na pluralidade, em encontros os mais diversos e tênues, nos quais, ele afeta e é afetado por diferentes paixões. O trabalho do ACS é em si potência, diversidade, indefinição, busca, rupturas, contratualidades e fugas.

\section{Colaboradores}

Heletícia Scabelo Galavote foi responsável pela elaboração do tema, construção do quadro teórico, produção dos dados, análise e delineamento final do estudo. Túlio Batista Franco colaborou na elaboração do tema, construção do quadro teórico, na análise e revisão final. Rita de Cássia Duarte Lima participou da construção do quadro teórico, análise e revisão final.

\section{Referências}

BARROS, M.E.B. De amoladores de faca a cartógrafos: a atividade do cuidado. In: PINHEIRO, R.; MATTOS, R.A. (Orgs.). Cuidar do cuidado: responsabilidade com a integralidade das ações de saúde. Rio de Janeiro: LAPPIS, 2008. p.279-95.

CAMPOS, G.W.S. Saúde pública e saúde coletiva: campo e núcleo de saberes e práticas. Cienc. Saude Colet., v.5, n.2, p.219-30, 2000.

DELEUZE, G. Espinosa: filosofia prática. São Paulo: Escuta, 2002.

. Empirismo e subjetividade: ensaio sobre a natureza humana segundo Hume. São Paulo: Editora 34, 2001.

Mil platôs: capitalismo e esquizofrenia. São Paulo: Editora 34, 1996. v.3.

Proust e os signos. Rio de Janeiro: Forense Universitária, 1987.

FERREIRA, V.S.C. Micropolítica do processo de trabalho do Agente Comunitário de Saúde: território de produção de cuidado e subjetividades. 2008. Tese (Doutorado) Universidade Federal do Rio de Janeiro, Rio de Janeiro. 2008.

FOUCAULT, M. O nascimento da clínica. Rio de Janeiro: Forense Universitária, 2004.

FRANCO, T.B. As redes na micropolítica do processo de trabalho em saúde. In: PINHEIRO, R.; MATTOS, R.A. (Orgs.). Gestão em redes: práticas de avaliação, formação e participação na saúde. Rio de Janeiro: Abrasco, 2006. p.459-74.

FRANCO, T.B.; GALAVOTE, H.S. Em busca da clínica dos afetos. In: FRANCO, T.B.; RAMOS, V.C. (Orgs.). Semiótica, afecção e cuidado em saúde. São Paulo: Hucitec, 2010. p.176-99.

FRANCO, T.B.; MERHY, E.E. El reconocimiento de la producción subjetiva del cuidado. Rev. Salud Colect., v.7, n.1, p.9-20, 2011.

FRANCO, T.B.; BUENO, W.S.; MERHY, E.E. O acolhimento e os processos de trabalho em saúde: o caso de Betim (MG). Cad. Saude Publica, v.15, n.2, p.345-53, 1999. 
GALAVOTE, H.S. Alegrias e tristezas no cotidiano de trabalho do agente comunitário de saúde: cenários de paixões e afetamentos. 2010, Dissertação (Mestrado) Programa de Pós-Graduação em Saúde Coletiva, Universidade Federal Fluminense, Niterói. 2010.

. Desvendando os processos de trabalho do agente comunitário de saúde nos cenários revelados na Estratégia Saúde da Família no município de Vitória, ES, Brasil. Cienc. Saude Colet., v.16, n.1, p.231-40, 2007.

GUATTARI, F.; ROLNIK, S. Micropolítica: cartografias do desejo. Petrópolis: Vozes, 2005.

MENDONÇA, P.E.X. (LUTA) Em defesa da vida: tensão e conflito, reconhecimento e desrespeito nas práticas de gestão do Sistema Único de Saúde. 2008. Dissertação (Mestrado) - Universidade Federal do Rio de Janeiro, Rio de Janeiro. 2008.

MERHY, E.E. Saúde: a cartografia do trabalho vivo em ato. 2.ed. São Paulo: Hucitec, 2002.

MERHY, E.E.; FRANCO, T.B. Por uma composição técnica do trabalho centrada nas tecnologias leves e no campo relacional. Saude Debate, v.27, n.65, p.316-23, 2003

ROLNIK, S. Cartografia sentimental: transformações contemporâneas do desejo. Rio Grande do Sul: Sulina, 2006.

SANTOS, S.B.; BARROS, E.B. Trabalhador da Saúde: protagonismo dos trabalhadores na gestão do trabalho em Saúde. Rio Grande do Sul: Unijul, 2007.

SILVA, J.A.; DALMASO, A.S.W. Agente Comunitário de Saúde: o ser, o saber, o fazer. Rio de Janeiro: Fiocruz, 2006.

SILVA, J.A.; DALMASO, A.S. O agente comunitário de saúde e suas atribuições: os desafios para os processos de formação de recursos humanos em saúde. Interface (Botucatu), v.6, n.10, p.75-83, 2002.

GALAVOTE, H.S. et al. Las alegrías y las penas de trabajo en diario del agente comunitario de salud: escenas de pasiones y afecciones. Interface (Botucatu), v.17, n.46, p.575-86, jul./set. 2013.

Este estudio trata de mostrar el proceso de trabajo del agente comunitario de salud (ACS), basado en la teoría de las afecciones de Espinosa. Considera el encuentro como una unidad de análisis, buscando entenderlo en su dinámica de producción del cuidado, analizando las afecciones que se se expresan por alegrías y tristezas y sus efectos en el trabajo del ACS. Se trata de un estudio explorativo-descriptivo, de carácter cualitativo, realizado en la Unidad Jardim Catarina Jardim, São Gonçalo, Río de Janeiro, Brasil. Los datos fueron recolectados con diez ACSs por medio de guión semiestructurado y observación etnográfica. El estudio revela un ACS múltiple, expuesto a las afecciones de las relaciones que mantiene, variando entre el reconocimiento y la sumisión a las lógicas instituidas, resultando en alegría y tristeza, aumento y reducción de su capacidad de acción, respectivamente.

Palabras clave: Salud de la familia. Agentes comunitarios de salud. Subjetividad. 